\title{
Extremely rare case of anterior tracheal rupture following endotracheal intubation
}

\author{
Upayangani Fernando, ${ }^{1 *}$ Jayasundara Mudiyanselage Ramitha Jayasundara ${ }^{2}$ \\ Medical Officer in Anaesthesiology ${ }^{1 *}$, Consultant Anaesthetist ${ }^{2}$, District General Hospital, Vavuniya, \\ Sri Lanka.
}

\begin{abstract}
Tracheal rupture is a very rare complication of endotracheal intubation and anterior tears become extremely rare. It is associated with potentially devastating complications which increases perioperative mortality and morbidity. We report a young maternal patient who sustained an anterior tracheal tear complicated with subcutaneous emphysema, pneumomediastinum, bilateral tension pneumothoraces and two episodes of peri-arrest. We emphasize on it's risk factors, importance of early diagnosis and practical approach of management. She was conservatively managed in a general ICU and had a successful outcome without sequelae.
\end{abstract}

Keywords: Tracheal rupture; anterior tracheal rupture; subcutaneous emphysema; bilateral pneumothorax

\section{Introduction}

Iatrogenic tracheal rupture is a rare complication of general anaesthesia. Endotracheal intubation is the commonest ${ }^{1,5}$ cause of iatrogenic tracheal rupture which typically involves posterior tracheal wall. ${ }^{2}$ Incidence of post intubation tracheal rupture ranges between $1: 20000^{2,3}$ and 1:75000 2,6 and anterior tracheal tears are extremely rare. Patient may be asymptomatic or complicated with subcutaneous emphysema, respiratory insufficiency with pneumothorax and cardiac compromise with pneumo mediastinum. High index of clinical suspicion is the key to diagnosis. Bronchoscopy, chest $\mathrm{X}$ ray and non contrastCTchest are useful to confirm diagnosis. ${ }^{2}$ Tracheal rupture is traditionally being managed with surgical repair. ${ }^{1}$ However conservative management is the current trend. ${ }^{2}$

\section{Case report}

A previously well, 19-year-old primi mother (height $148 \mathrm{~cm}$ ) with breech presentation in labour presented for emergency LSCS.

\section{*Correspondence: Upayangani Fernando E mail: upayangi@gmail.com}

https://orcid.org/0000-0003-3963-795X

Received: 17/01/2019

Accepted:11/05/2019

DOI: http://doi.org/10.4038/slja.v27i2.8403

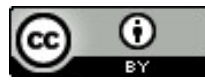

During preoperative assessment she was devoid of pregnancy related medical problems but found to have acute upper and lower respiratory tract infections. $0.3 \mathrm{M}$ sodium citrate $30 \mathrm{ml}$ was given considering inadequate fasting and high risk of aspiration. Trials of subarachnoid block attempted by experienced anaesthetists (MOA) failed to achieve adequate block twice, taking more than 30 minutes of time. Considering the emergency situation, she was converted to GA with rapid sequence induction under supervision of consultant anaesthetist. After preoxygenation, thiopentone $300 \mathrm{mg}$ and suxamethonium $100 \mathrm{mg}$ i.v. was given. Then, she was gently intubated with size $7.0 \mathrm{~mm}$ ETT at $1^{\text {st }}$ attempt without bougie assistance. Cuff was inflated with $5 \mathrm{ml}$ of air and correct placement was confirmed at lip level of $19 \mathrm{~cm}$. IPPV was provided with tidal volume (TV) of $7 \mathrm{ml} / \mathrm{kg}$ while maintaining anaesthesia with isoflurane. LSCS was carried out successfully over 20-30 minutes. All the AAGBI monitoring parameters were well maintained within normal ranges without additional assistance throughout surgery.

During recovery, patient bucked on ETT and a significant cough developed. Within next few minutes facial oedema developed, and sudden bradycardia ensued which was managed with i.v. atropine. Airway pressure started rising while $\mathrm{S}_{\mathrm{P}} \mathrm{O}_{2}$ dropped slowly. Patient was ventilated manually with $100 \% \mathrm{O}_{2}$ to improve oxygenation. 
Consultant anaesthetist was summoned and subcutaneous emphysema was detected extending from face up to mid thorax. Clinical suspicion of tracheal rupture was made excluding other possibilities of subcutaneous emphysema. On further examination trachea was in midline and bilateral air entry was equal with adequate chest expansion at that moment. Saturation was maintained with $\mathrm{FiO}_{2}$ of 0.3 and low tidal volumes. Anaesthesia was then deepened with inhalational agents and patient was transferred to ICU within 10-15 minutes without extubating for further management.

Patient was sedated and ventilated with SIMV mode while monitoring vital parameters . Respiratory distress developed gradually within next hour in ICU and another episode of peri arrest bradycardia was managed with anticholinergics.

Chest $\mathrm{X}$ ray revealed bilateral pneumothoraces with trachea in midline (Figure 1). Bilateral tension pneumothoraces were relieved by bilateral needle thoracocentesis. Remarkable improvement of vital parameters was observed with improved saturation and bilateral intercostaldrains were inserted.

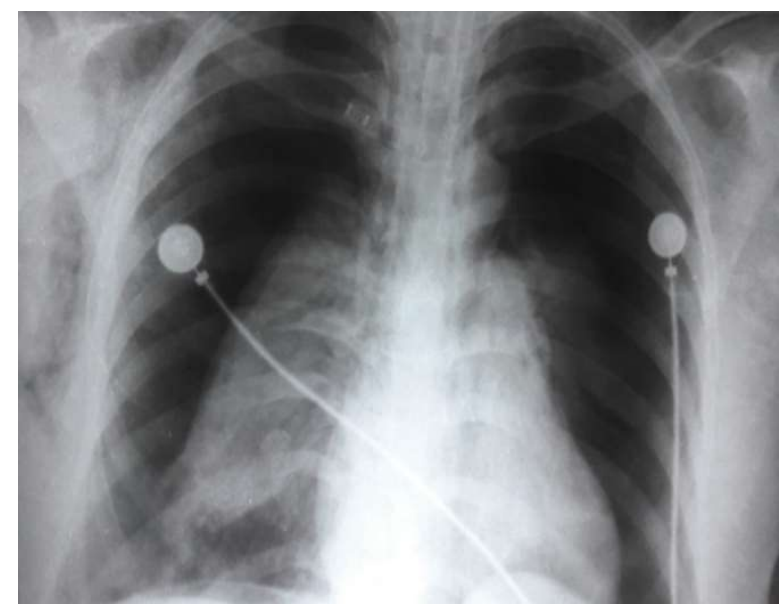

Figure 1: Chest $X$ ray showing trachea in midline with bilateral pneumothoraces

Once the cardiovascular stability was achieved noncontrast CTchest and neck was arranged which confirmed anterior tracheal rupture. Findings were,

1. Discontinuity in the anterior tracheal wall 5 to $6 \mathrm{~cm}$ from carina inferior to tip of ETT.

(Figure 2)
2. Bilateral pneumothoraces, pneumomediastinam and extensive subcutaneous emphysema.

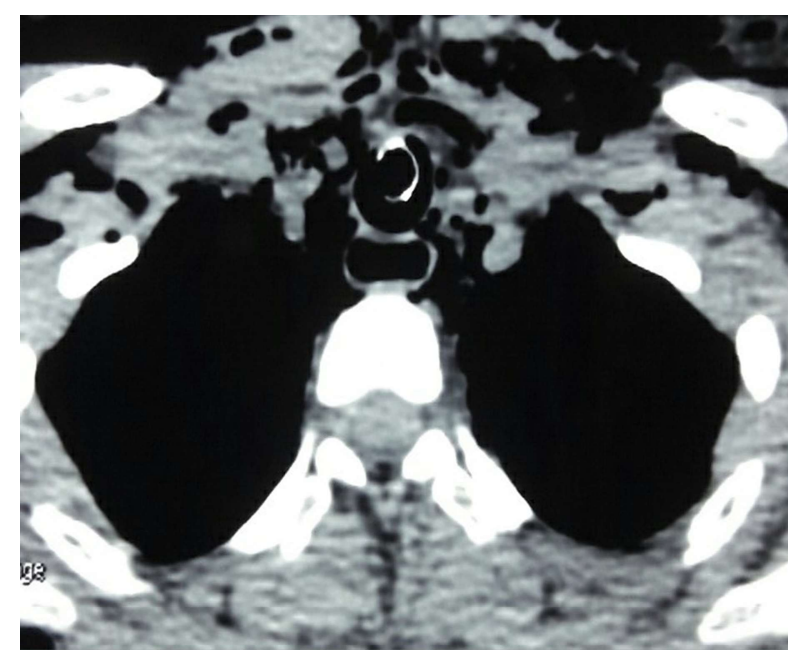

Figure 2: Non-contrast CT chest showing discontinuity of anterior tracheal wall

Conservative management with minimal ventilatory support were well tolerated by patient. Necessity of surgical repair or other intervention to seal the tear were largely discouraged by rapid improvement of her clinical picture. Continuous air leakage from tear was excluded clinically with subsiding subcutaneous emphysema and resolving pneumothorax. Broad spectrum intravenous antibiotics were administered to cover upper and lower respiratory tract infection and to avoid mediastinitis. Other supportive care (eg: nebulization, chest physiotherapy) was given to improve her pulmonary function. Patient was successfully extubated within 24 hours of incident. Oral feeding was well tolerated following extubation. Subsequently, intercostal drains were removed on Day 3 and patient was discharged to ward on $4^{\text {th }}$ day after successful management of tracheal rupture without sequalae. Patient was discharged from the ward on Day 07 with complete recovery.

\section{Discussion}

Tracheal rupture is a rare complication of endotracheal intubation. The exact mechanism of injury is uncertain. ${ }^{1}$ Series of risk factors ${ }^{1}$ has been identified such as female gender, short stature, emergency intubation ${ }^{2,4,5}$, bucking on ETT and significant cough which were present in our patient. Acute upper and lower respiratory tract infection 
worsens this risk and hyperreactive airway induces vigorous coughing. Possibility of minute congenital tracheal abnormality ${ }^{2,4}$ cannot be excluded.

Typically post intubation tracheal rupture occurs in posterior membranous trachea. ${ }^{1-4}$ However, our case was an exception due to involvement of anterior tracheal wall.

The most common clinical manifestations of tracheal rupture are subcutaneous emphysema, pneumomediastinum and pneumothorax. ${ }^{1,3}$ These manifestations may vary in significance and patient may be even asymptomatic. Diagnosis is based on high clinical suspicion. Our patient was complicated with development of subcutaneous emphysema, bilateral tension pneumothorax and peri arrest bradycardia, latter of which could have been induced by pneumomediastinum.

Direct visualization by bronchoscopy is essential ${ }^{4}$ to diagnose tracheal rupture, which was unavailable in our hospital. Hence, non-contrast CT neck and chest was used to confirm tracheal damage.

Two types of treatment for tracheal rupture being implemented is guided by location and size of tear, patient's clinical stability and complications. Surgical repair is traditionally recommended but is associated with high mortality., ${ }^{2,5}$ Conservative management has a growing body of evidence of success. ${ }^{5}$ It was previously implemented for smaller $(<2 \mathrm{~cm})$ tracheal tears with delayed diagnosis and for patients in a poor clinical condition. ${ }^{2,5}$ Criteria for conservative methods are now being extended in patients with cardiovascular stability, absence of oesophageal injury, and in non-progressive mediastinal and subcutaneous emphysema in absence of sepsis., ${ }^{3,5}$

\section{Conclusion}

Anterior tracheal rupture is extremely rare following endotracheal intubation.This young obstertric patient who sustained anterior tracheal rupture following intubation had life threatening complications. Early recognition of subcutaneuos emphysema with clinical suspicion of tracheal rupture, recognition of bilateral pneumothoraces and immediate management with needle thoracocentecis lead this patient to manage conservatively with successful outcome.

\section{References}

1. Minambres E, Buron J, Ballesteres $\mathrm{M}$ A et al. Tracheal rupture after endotracheal intubation: a literature systematic review. EJCTS 2009;35(6):1056-1062 https://doi.org/10.1016/j.ejcts.2009.01.053 PMid:19369087

2. Ovari A, Just T, Pau H. Conservative management of post intubation tracheal tears-report of three cases. J Thorac Dis.2014;6(6): E85-E91

3. Singh S, Gurney S. Management of post-intubation tracheal membrane ruptures: A practical approach. Indian J Crit Care Med 2013;17:99-103 https://doi.org/10.4103/0972-5229.114826 PMid:23983415 PMCid:PMC3752875

4.Chang C, Cheng S, Chang S. Conservative Treatment of Severe Tracheal Laceration After Endotracheal Intubation. Respiratory Care 2011;56 (6):861-862 https://doi.org/10.4187/respcare.00891 PMid:21333080

5.Wallet F, Schoeffler M, Duperret $S$ et al. Management of Low Tracheal Rupture in Patients Requiring Mechanical Ventilation for Acute Respiratory Distress Syndrome. Anesthesiology 1 2008;108:159-162 https://doi.org/10.1097/01.anes.0000296104.46682. $\underline{\mathrm{ca}}$ PMid:18156895

6. Sachneider T, Volz K, Dienemann H et al. Incidence and treatment modalities of tracheobronchial injuries in Germany. Interact Cardiovasc Thorac Surg 2009;8:571-6 https://doi.org/10.1510/icvts.2008.196790

PMid:19211582 